\title{
Employee's Perception on Workplace Gossip in the South African Public Sectors: The Implication on Job Performance
}

\author{
Dlamini Phakamani Irvine ${ }^{1} \&$ Mdletshe Bonga Blessing ${ }^{1}$ \\ ${ }^{1}$ Huazhong University of Science and Technology, Wuhan, China \\ Correspondence: Dlamini Phakamani Irvine, Huazhong University of Science and Technology, Wuhan, China.
}

Received: March 5, 2019

Accepted: March 24, 2019

Online Published: May 27, 2019

doi:10.5430/jms.v10n3p48

URL: https://doi.org/10.5430/jms.v10n3p48

\begin{abstract}
Gossip is pervasive in any working environment. Sketching upon the existing and scant body of research knowledge surrounding the subject of gossip, the current qualitative study undertaken critically assessed how the employees protrude themselves after being victims of gossip in a workplace. This study examined the influence of workplace gossip on the job performance of employees within selected municipalities in South Africa. The researcher intended to establish the likeliest behaviour of municipality employees towards their job performance in the event of encountering workplace gossip. Interviews with twenty-five office workers were conducted and data documented and analyzed. The heuristic of this study was to equip managers or those in practice with an in-depth understanding about office gossip, by providing a new dimension about the influence workplace gossip on job performance and employees self-efficacy. Moreover, the study necessitated an in-depth understanding of several reactions that emanates from employees behavioral patterns when affected by office gossip. The study uncovered a substantial outcome, such that if gossip is work-related, rather than non-work-related, employees are more likely to improve their performance. However, unremittingly exposure to gossip can have a negative impact on employee's self-efficacy.
\end{abstract}

Keywords: workplace gossip, employees' perception, self- efficacy, job performance

\section{Introduction}

Gossip is a phenomenon found almost in every place that has interacting people, of which the workplace is not an exception. The workplace is often regarded as the richest ground that enables gossip to flourish (Farley, Timme, \& Hart, 2010). Perhaps, this can be attributed to the sociable environment and that employees spend more time in the workplace than in their homes. It is such time that gossip finds itself developing from mere chitchats into serious gossip which might be generic or malicious (Gobind \& Ukpere, 2013)Garber, (2011). The malicious gossip, or that which is intended to do harm, is considered equivalent to misconduct, at least in the South African workplace (Gobind \& Ukpere, 2013). None of the organizations is insulated from gossip in the workplace be it private or public. Gossip is used in the workplace for a variety of reasons. Farley et al. (2010) indicate that sometimes, employees use gossip as a mechanism for coping with work-related stress. Another view byYang, Minjock, Voss, and Colarelli (2014) is that employees' gossip to get along with an abusive supervisor.

(Gobind \& Ukpere, 2013) further cautions about the negative outcomes if gossip is underestimated by employers, suggesting that there could be increased staff turnover, premature resignations and loss of valuable employees as a result of gossip. In supporting this argument, (Abbajay, 2013) posit that workplace gossip can further pose a threat to the organisational performance by affecting the productivity and depleting of resources of energy and resources. Decoster et al. (2013) affirm that the consequences of gossiping behaviour are not limited to individuals as the organisation could also be severely affected. Luna and Shih Yung (2013) further state that the organizational culture and organizational learning are the ones which are mostly affected because gossip reshapes employees' perceptions

Fernandes, Kapoor, and Karandikar (2017) define gossip as the provision of information by one person to another about an absent third person. Another slightly different definition is posited by Foster (2004) who views gossip as the practice of producing, hearing or participating in evaluative comments about someone. The workplace gossip, on the other hand, is defined by Ellwardt, Wittek, and Wielers (2012) as an informal and evaluative conversation in an organization about another member within the organization who is not present during that conversation. Kurland and Pelled (2000), state that an evaluative talk refers a conversation meant to assess the individual in terms of their work 
and personal life. Though there is an accepted definition of workplace gossip, however for gossip to become a workplace gossip Wu, Birtch, Chiang, and Zhang (2018) insist that it should meet a certain criteria and describe it as follows: gossip should firstly be targeted to an individual, secondly, be evaluative in nature, thirdly occur in a social setting where the target is known to both gossiper and the recipients and lastly disseminated in the absence of the target.

\section{Literature Review and Theoretically Framing}

Gossip is an instrumental tool to facilitate the flow of information from one person to another about the third part absent from the discussion. This flow of information occurs in a spontaneous manner, from the gossiper to a recipient. In most cases, the gossiper is without any prejudices of being held liable or accountable on his or her sharing's because of the assurance of privacy (Ben-Ze'ev, 1994). Though there might be damaging issues and controversies embedded on the workplace gossip, some organizations tend to regard it as an essential tool for disseminating information within the organisations(Yang et al., 2014). Further to that, workplace gossip can be an effective mechanism to ascertain the emotional well-being of employees in relation to certain policies and procedural aspect of the work environment

According to Chua and de la Cerna Uy (2014), workplace gossip is an activity which sometimes, individuals engage because they need a leisure time, in a form of entertainment, or perhaps recreation. Employees may find themselves with ample time at their disposal which could lead to boredom, and simply wish to escape reality and monotony, thereby indulging in the guilty pleasure of gossiping. In gossip, employees are likely to find it enjoyable, amusing or pleasurable. Fox (2001), contend that individuals experience gossip as an exciting form of risk taking part in something that is slightly mischievous.

Through gossip, employees find associations. Gossip has the power to draw people together especially among the ones who share common interests (Chua \& de la Cerna Uy, 2014). Hamman and Kruger (2017) state that gossip improves people's understanding about each other and it further strengthens their relationship. Fernandes et al. (2017), asserts that gossip is considered as an effective tool, to create social groups, and further provides an opportunity for people to learn new things and to be known as a new group.Carrim (2016), opines that for organisations and researchers to understand workplace better, it is essential to acknowledge that intergroup relations, group association might shape interaction at a micro level or at a personal level. Ferrari (2015), reveals that a group setting can provide a flourishing platform for workplace gossip. This might be influenced by shared values and cultural ethics among members from the same or cognate group.

Some researchers tend to classify workplace gossip (WG) as retaliating tool employees get equal with the employer while they display a deviant behaviour. Pathak (2014), point out that WG might also tarnish the organizational norms severely and in that the employee's wellbeing may equally be compromised. Cole and Scrivener (2013), argues that the absence of organisational norms expose employees to workplace bullying through workplace gossip. The vacuum left by the organisational norms enables other employees to take advantage of the situation by bullying others in the form of gossip. Essentially, workplace gossip might contribute with pandemonium in the organisation.

There are other arguments by some researchers which seem to place different perspective about workplace gossip. Van der Merwe (2005), as well as Spreitzer and Sonenshein (2004), argues that workplace gossip can manifest in either positive or negative form. A positive form of gossip is viewed as light-hearted, idle, meaningless chit-chat about a colleague, neighbour or any other person as a subject matter. It is usually done for a purpose satisfying curiosity. The negative form of gossip refers to intentionally speaking ill of another person or negative facts of a third party's character, appearance, or behavior behind the person's back which leads to workplace ostracism (Zhao, Peng, \& Sheard, 2013).

These researchers state that workplace gossip should be understood from a two continuum namely job-related gossip (JRG) and non-job-related gossip (NJG). Kurland and Pelled (2000), have taken a much more fundamental view of differentiating job-related gossip with non-job related gossip. According to them, job related gossip focus on the subjects work life, such as job performance and career developments. For example, being promoted, fired, transferred or demoted. On the other hand, non-job related gossip predominantly focuses on the personal life of an individual such as family matters, illness and marriage. There are various reasons that could influence employees to engage in workplace gossip. Research points to retaliation towards an abusive supervisor (Zhao et al., 2013), recreational purposes (Wu et al., 2018) and when they want to cope with work-related stress(Alshehre, 2017). Whether the information shared during gossip is work related or non-work related it could have a significant effect on the organizational performance since it involves individual employees. 
The overarching framework that this study is based on is social cognitive theory as was introduced by Bandura around 1970s, and it is meant for understanding motivation and behavior of individuals. Kurose (2013) indicates that social cognitive theory sees motivation and behavior resulting from an ongoing dynamic interaction among cognitive, social and environmental variables. Furthermore, people are influenced by the social systems within which they exist, yet their surroundings may not necessarily define them. The emphasis of this theory is that a person's behavior is determined by their self-efficacy. In a broader sense, self-efficacy is a feature which is influential in the formation of behavior and individual's judgment about his/her capacity to organize the necessary activities to perform a certain task and achieve it successfully (Bandura, 1986).

The rationale for adopting self-efficacy as the general framework to set the tone for the discussion lies on the factors that are central to this study namely employee job performance and workplace gossip. Self-efficacy is known to be instrumental when one study individuals' behavior and another researcher, Decoster, Camps, Stouten, Vandevyvere, and Tripp (2013), affirms self-efficacy theory in relation to studying about employees' job performance by the assertion that employees with high self-efficacy beliefs tend to be satisfied with their job. This assertion is further supported by Cherian and Jacob (2013), who emphasizes that self-efficacy has an impact on an individuals' emotional reaction and thought patterns.

Generally, people rely on their psychological state of mind to perform any task at hand. Bandura (1986) indicates that the high arousal of emotions usually, incapacitates performance. Since gossip is evaluative in nature, it is therefore inevitable that it has a higher proximity to trigger some emotions on victims (employees). One wonders how employee's job performance could be affected by workplace gossip. An employee's job performance commonly incorporates both behaviors (what an employee does) and the outcome.

The job performance does not include the end results of an employee's behavior, but rather performance relates to behavioral patterns of an employee (Alshehre, 2017). Kuo et al. (2015) claim that if gossip is not job-related, most employees would not treat it seriously because it is general and relates to social factors (such as love or relationship affairs, or well-being of family members. They further reiterate that such gossip may not provoke an employee to respond intensely. Van Vuuren (2014) outline that gossiping in an organization could be view as a tool for the workplace bullying. Based on the literature, the workplace gossip has a potential of resulting in some negative reactions such as low staff morale, low motivation, attrition of valuable employees (Gobind \& Ukpere, 2013).

\section{Motivation of the Study}

The functionality of the municipalities depends on its employees and thus far, most municipalities have an organizational performance challenge. Ellwardt et al. (2012), state that it is essential for municipal officers to realise that the inefficiency and ineffectiveness of services delivery have far-reaching consequences mainly because the welfare of the citizens depend on the decisions made by municipalities. There are numerous problems that could be attributed to the inefficiency of municipalities, for example, low staff morale, lack skilled personnel or lack of a coordinated strategic plan. Mashamaite (2014) also states that some of the senior officials in most municipalities get involved in corrupt and fraudulent conduct. The political interference is another challenge that researchers have investigated on South African municipalities and found that when there is lower political interference on human resource management, employees are likely to show signs of higher commitment, better employee citizenship behavior and consequently better service quality Dzansi, Chipunza, and Monnapula-Mapesela (2016).

There has not been a study that links the municipality inefficiency to workplace gossip behaviour. Therefore, workplace gossip may not be dismissed as a factor that affects the municipality operations through employee poor job performance. Bhasin (2013) indicates that workplace gossip may impact the overall employee performance and eventually lead to a workforce that does not trust management which ultimately causes alienation and employee disengagement

\subsection{Research Questions}

The two research questions specified below are used to direct the study:

1. How do municipality employees perceive workplace gossip in the work environment?

2. How does workplace gossip impact municipality employee's willingness to perform at work?

\section{Methodology}

In view of the fact that gossip is pervasive in a workplace, the study attempts to shed new insight on the perceptions of employees on workplace gossip. The qualitative research method was utilized. Mouton, (2004) asserts that the 
most appropriate way of investigating any subject in-depth is through the adoption of qualitative approach, hence qualitative researchers are a concern with a process rather than an end results of a subject.

\subsection{Study Design}

To discover some in-depth understanding of the perception of employees about workplace gossip this study was entrenched in a multi-place case study design. In qualitative research methodology, a researcher seeks to institute the meaning of a phenomenon from the interpretations of participants (Creswell \& Creswell, 2017). In view of that employees exudes variants behaviours when confronted with workplace gossip, the study entrenched phenomenology methodological approach. Phenomenological in its broadest sense it encompasses direct experiences taken at a face value of participants, and behaviours portrayed by individuals when confronted by phenomena investigated. Moreover, the strength of this approach is that it is grounded on the understanding of daily life situations of individuals (Cohen, Manion, \& Morrison, 2011).

\subsection{Participants and Data Collection}

Based on the ideology that an employee's tendency to gossip is ubiquitous in any organization, participants were selected utilizing convenience sampling. Sample constituted of 25 employees from urban, semi-urban and rural settings where the municipalities are located. Participants were assured entirely of confidentiality and their comments and contributions will be used for the purpose of this current study only.

Data was collected in two phases. In the first phase, a semi-structured interview which lasted between 30 and 40 minutes was done with each participant. Subsequently, a week later participants were requested to complete an open-ended questionnaire. This was done with a motive of establishing consistency in their responses. Various responses were received from participants. However, data from the interview was reduced in order to preserve data that mainly focus on the intentions of this study.

Table 1. Profile of participants

\begin{tabular}{llll}
\hline No & Gender (Male/ Female) & Age & Occupation \\
\hline 1 & Female & $25-30$ & General Worker \\
\hline 2 & Female & $25-30$ & Intern \\
\hline 3 & Female & $25-30$ & Junior Accountant \\
\hline 4 & Female & $40-45$ & Secretary \\
\hline 5 & Male & $30-35$ & General Worker \\
\hline 6 & Male & $30-35$ & Technician \\
\hline 7 & Female & $30-35$ & General Worker \\
\hline 8 & Female & $45-50$ & General Worker \\
\hline 9 & Male & $25-30$ & Technician \\
\hline 10 & Male & $25-30$ & Communication officer \\
\hline 11 & Male & $30-35$ & Data Capturer \\
\hline 12 & Female & $45-50$ & Communication Manager \\
\hline 13 & Male & $40-45$ & Finance Manager \\
\hline 14 & Female & $30-35$ & Field Worker \\
\hline 15 & Male & $30-35$ & Field worker \\
\hline 16 & Male & $40-45$ & Technician \\
\hline 17 & Female & $30-35$ & IT Specialist \\
\hline 18 & Female & $30-35$ & General Worker \\
\hline 19 & Male & $35-40$ & Data Capturer \\
\hline 20 & Male & $35-40$ & Receptionist \\
\hline & & & \\
\hline
\end{tabular}




\begin{tabular}{llll}
\hline 21 & Female & $35-40$ & Finance Manager \\
\hline 22 & Female & $40-45$ & Senior Accountant \\
\hline 23 & Female & $35-40$ & Administration Officer \\
\hline 24 & Male & $25-30$ & General Worker \\
\hline 25 & Female & $25-30$ & Technician \\
\hline
\end{tabular}

\subsection{Data Analysis}

The researcher compared the responses from interviews with ones from the open-ended questionnaire to detect recurring themes. Interviews and open-ended questionnaires were meticulously analysed in order to identify themes that emerged from data. It is worth to further outline that the comprehensive data was accumulated from the interview process. Consequently, the interview data were analysed using thematic analysis.

Thematic analysis is presumed to be appropriate in this study because it allows feasibility in interpreting perceptions of employees pertaining workplace gossip. Thematic analysis affords flexibility to code and categorises data into themes. For example, how matters influence the perceptions of participants in such instance, data can be presented and classified according to its similarities and differences Alhojailan, (2012). Data organization and interpretation were established towards the precise direction of the study.

\section{Findings}

In this study, the investigation was on the perception of employees with regard to workplace gossip. Furthermore, the essence of this paper was to establish that how workplace gossip affects employee's willingness to perform in an organization. The following themes have unfolded in the study.

\subsection{Nature of Workplace Gossip}

Most, participants (21) concurred that gossip is inevitable in any settings where there are human interactions. In addition, participants undoubtedly revealed that in organizational settings gossip is seen as a tool that is effective and widely use to disseminate information with the organization. This finding supports many scholars of workplace gossip, such as Yang et al, (2014) who assert that regardless of all deleterious issues and controversies embedded towards workplace gossip, employees consider it as an essential tool for disseminating information and communication. Majority of participants (18) felt that workplace gossip cannot entirely be denounced. Participants unearth that it is significant to consider the premise of gossip. For example, whether gossip was influence with moral or non-moral motives. One of the participants reported that: "Through gossiping one could easily caution other fellow colleges about certain individual's behavioral patterns that can hamper their well-being in an organization"

(Fernandes et al., 2017) postulate that individuals are prone to gossip when the person being gossiped about violate moral values in social settings. Thus, it can be assumed that there might be a close linkage between well-being of employees and workplace gossip. A number of participants (19) reported that their ability to perform at work after being victims of gossip relies on the nature of gossip. For example, if there is a spectrum of gossip that is non-job-related (personal affairs) that could lead to drastically psychological changes among employees, irrespective of whether that gossip is directly or not directly affecting you.

\subsection{Source of Workplace Gossip}

All participants in one accord ventilated that, overhearing your boss gossiping about another coworker tends to be detrimental to the reputation of that individual boss. For example, one participant reported that: My boss is a gossiper. He gossips to me about lot personal stuff that is taking place in other staff members, Recently, he has just revealed to me HIV status of one of the staff members, seriously that is really bothering me (Respondent, 6).

When the source of gossip arises from senior people, it is shown to have a significant negative impact on employee's behavior and performance. Another participant reported that: My supervisor sees no problem in sharing others people the personal reason for not coming to work, she even goes to an extent of exposing your work-related mistakes to others colleagues (Respondent, 9).

The researcher finds out that gossip seems to be less effective when it originates from the same ranking levels of employees. Much has been ventilated in the management literature about gossiping strengthening social bonds among employees (Chua \& de la Cerna Uy, 2014). Therefore, paradoxically the metaphor of workplace gossip has been interwoven to provide the bad and the good side of office gossip. 


\subsection{The Implication of Workplace Gossip on Performance}

The wide perception held by most participants was that after being confronted by non- job-related gossip (personal affairs) such as social problems and any other problem pertinent to your personal affairs that reduces the art of willingness to perform at work. One of the participants reported that: Really, I personally do not feel contend after hearing that, some coworker were discussing my personal life behind my, back it really gets into my deepest nerve and I seriously don't think that could make us work effectively after hearing that, l was discussed in my absentia, particularly my private life!

The above sentiment share about this participant can give us an indication that if gossip is non- job-related at a workplace it might have more detrimental impact on the performance and behaviors of employees affected. Conversely, gossip that encompasses occupational matters appears to have both positive and negative impact on employee's performance. One participant reported that: To, find out that one of your colleagues is being praised by your boss for punctuality at work, that on it's owns makes you want to intimidate the same attitude, even though punctuality might be regarded as a trivial issue in some organization (Respondent 4).

The above example demonstrates that gossip may not simply inhibit immoral behavior but it might also serve as a tool in motivating employees to be more engaged at work.

\subsection{Self-Efficacy and Malicious Workplace Gossip on Performance}

The study revealed that self-efficacy has an impact on individual's reaction to malicious workplace gossip. It is interesting to report that participants have displayed diversified reactions towards malicious office gossip. One participant alluded that: If a person share my personal affairs with another, I don't speedily react on that, even though it might be something bad that I have committed, the main reason is that, people always have something to say about other people's affairs (Respondent 2).

With regard to the above-mentioned sentiments, the main idea is that self-efficacy can be an indelible determinant on how an individual behaves in the midst of galvanizing emotions by gossip. It has been alluded by most participants (19) that malicious gossip induces some counterproductive work behavior, particularly if it's emerged from seniors. One participant outlines that: I don't think, that I would be able to respect a boss, who gossip negatively about me or any other particular individual for that matter. Once I find out that my boss was sharing negative things about me, in my absentia I would deliberately behave badly, up until she confront me! (Respondent, 11).

\section{Discussion and Implication}

Constructing on social cognitive theory Bandura (1986), the study attempted to understand individual behavioral patterns in an event where there is the target of malicious or aggressive gossip. The study incorporated workplace gossip with self -efficacy concept which is considered to be a predominantly empirically concept under social cognitive theory. Self-efficacy helps us to establish how much effort people will utilize when they have been the task of an activity. Moreover, it also assists us in determining the endurance of people when dealing with hostile situations. The higher the essence of self -efficacy, the better the strength, persistence, and resilience(Pathak, 2014).

Firstly, the results indicated that the nature of workplace gossip plays a pivotal role in determining employee's performance. This furnishes us with an essence of what gossip is acceptable and unacceptable at work. The study also revealed that moral standard does function as invariant internal regulators to induce employees in engaging on gossip. The nature of workplace gossip plays a crucial role in shaping individuals thoughts, actions, feelings and behavior. Findings of this study suggest that there is a higher propensity for individuals to incur disincentives or to lack performance when the gossip deals with their personal affairs (non -job -related). The above narrative is not overlapping with what has been discovered by Yue (2013) as contemplated that organizational commitment tends to decline among employees in a case whereby personal gross gossip is circulating within an organization.

The novel contribution of this study is that most of the employees tend to condition their behavior at work based on the (positive or negative) job- related gossip. Correspondingly, the social cognitive theory, by Bandura (1986) explains human behavior in terms of three dimensions, which are personal factors, environmental influences, and behavior continually. Workplace gossip has a strong propensity to influence individual performance in an organization. However, it can induce motivation or either it can have some detrimental outcomes to an individual who is a target for gossip. Furthermore, findings also exhibited that job-related gossip has close links to a certain degree of performance and commitment in an organization. Any individual at work who have heard negative job-related gossip about his or her coworker will show more commitment to his or her work, in an attempt to minimize possibilities of being the next victim. People tend to enhance their level of cooperation in the response to 
the likelihood of gossip and reputation spreading (Wu et al., 2018). Finally, when employees overhear accolades remarks about another coworker that influences his or her willingness to perform at his or her best ability, with a motive of mimicking other coworkers behavior.

For the purpose of this study, the researcher proposed that source of workplace gossip shall be restructured into vertical workplace gossip and horizontal workplace gossip. According to the researcher's point of view, vertical workplace gossip (VWG) occurs when the flow of gossip will originate from the seniors of the organization and such gossip must target an individual who is a subordinate. Meanwhile, horizontal workplace gossip (HWG) is a diffusion of gossip that originates from individuals of the same hierarchy in an organization.

The present work established that to a large extent, gossip that emerged from employees who occupy similar status at work, and who are in same social status in a society (HWG), appears to be less destructive on employee's performance. While in some circumstances the frequency engagement in individual's private lives discussions (non-job related gossip) can induce toxic emotions to a gossip target. Thus, the performance of that individual who is a gossip target might negatively impair. Cole and Scrivener (2013), supports this finding as she pinpoints that excessively and overwhelming workplace gossip can further threaten the organizational performance. Nevertheless, it should be remembered that this analysis has focused on a particular type and source of workplace gossip. The study revealed that implications of workplace gossip may have a disproportionate impact on employee's performance, due to its source. This study also points to the impact of gossip on the individual's behavior (targets of gossip) if the gossip is perpetuated by seniors in an organization, (vertical workplace gossip). It can argue that gossip that derived from seniors of the organization can have different outcomes on individual's behaviors. When employees are confronted by excessive malicious gossip from seniors in their environmental settings, drawing from social cognitive theory, employees reciprocate in undesirable behavior's that could be a restrain in their performance. It is therefore reasonable to outline that the emotional reaction of some disgruntle employees because of malicious gossip from their senior's may reasonably influence the quality of their job future performance.

This finding is supported by Bennett and Robinson (2003) as they lamented that when employees perceive negative treatment from their seniors, they react with deviant behavior as a form of retaliation to the one who has mistreated them. While malicious gossip might reinforce deviant behavior among affected employees, it is imperative to outline that not all employees will react in a negative manner, when confronted with gossip from seniors. Employees who have invested enormous time and effort to perform well in an organization, in addition, who identify themselves with the organization tend to reflect less negativity when confronted with malicious gossip from seniors. The supremacy of gossip seems to be contingent on the relative source of gossip. It can conceptualize that, if employees are confronted with insurmountable negative or non-job related gossip from their seniors that could lead to a devastating impact on their performance.

\section{Future Outlook and Limitations}

There is still an obligation in advancing our understanding of workplace gossip effects on targeted individuals within an organization. It is conceivable that not all individuals who have been victims of the workplace will display similar reactions in an organization. Thus, it is imperative to understand the impact of gossiping workplace to individuals who have been long-standing with an organization, precisely individuals who have developed a sense of commitment in an organization and identify themselves with the organization. Based on the above narrative it is imperative to examine both negative and positive aspect of gossip in influencing well-being and performance of employees in an organization Brady, Brown, and Liang (2017). Nevertheless, no research is without any limitations. The study has utilized convenience sampling method, which is choosing any nearest participant without any precautions, and this might be a major shortcoming when it comes to the generalizability of findings. Semi-structured interviews and open-ended questionnaires were effectively used in data collection process because they permitted a researcher to deepen his understanding of this conundrum workplace gossip phenomenon. However, questionnaires did not allow a researcher to gain insightful information, because in their nature they force people to provide the simplistic response to complex issues.

\section{Conclusion}

Most scholars of workplace gossip have made an ample call to managers to minimize or eradicate office gossip within an organization (Gobind \& Ukpere, 2013; Van Vuuren, 2014; Wu et al., 2018). However, negative perception of workplace gossip can limit us to gain a deeper understanding of the influences that cause employees to engage in gossip. Furthermore, not only that gossip has a potential to promote social cohesion among employees, it can benefit an organization because in essence, some employees who have the high level of self-efficacy can maximize their performance, in order to protect themselves in becoming next target of gossip. Moreover, overhearing praises of 
other coworkers that could be a major motivation for most employees. The study find out that virtually in most cases, participants expressed emotional harm if malicious gossip will arises from organizational seniors, which thus might impair performance negatively. Despite the indicated limitations of this study, the findings of this current study have a potential to add significant value to a growing body of research on workplace gossiping. The study has also afforded new insight by enquiring the impact of workplace gossip on employee's performance and behavior, where the source is from bosses or coworkers. Thus, this has been a major contribution and extension to the literature of workplace gossip, since it provides another dimension of workplace gossip.

\section{References}

Abbajay, M. (2013). The danger of workplace gossip. https://doi.org/10.4236/ojmp.2017.62010

Alshehre, R. A. M. (2017). Positive Effects of Gossiping at Work. Open Journal of Medical Psychology, 6(02), 126.

Bandura, A. (1986). The explanatory and predictive scope of self-efficacy theory. Journal of Social and Clinical Psychology, 4(3), 359-373. https://doi.org/10.1521/jscp.1986.4.3.359

Ben-Ze'ev, A. (1994). The vindication of gossip.

Besnier, N. (1990). Conflict management, gossip, and affective meaning on Nukulaelae. Disentangling: Conflict Discourse in Pacific Societies, 290-334.

Brady, D. L., Brown, D. J., \& Liang, L. H. (2017). Moving beyond assumptions of deviance: The reconceptualization and measurement of workplace gossip. Journal of applied Psychology, 102(1), 1. https://doi.org/10.1037/ap10000164

Carrim, N. M. (2016). 'Shh... quiet! Here they come.'Black employees as targets of office gossip. Journal of Psychology in Africa, 26(2), 180-185. https://doi.org/10.1080/14330237.2016.1163912

Cherian, J., \& Jacob, J. (2013). Impact of self efficacy on motivation and performance of employees. International Journal of Business and Management, 8(14), 80. https://doi.org/10.5539/ijbm.v8n14p80

Chua, S. V., \& de la Cerna Uy, K. J. (2014). The Psychological Anatomy of Gossip. American Journal of Management, 14(3), 64.

Cohen, L., Manion, L., \& Morrison, K. (2011). Coding and content analysis. Research Methods in Education, 559-573.

Cole, J. M., \& Scrivener, H. (2013). Short term effects of gossip behavior on self-esteem. Current Psychology, 32(3), 252-260. https://doi.org/10.1007/s12144-013-9176-3

Creswell, J. W., \& Creswell, J. D. (2017). Research design: Qualitative, quantitative, and mixed methods approaches. Sage publications.

Decoster, S., Camps, J., Stouten, J., Vandevyvere, L., \& Tripp, T. M. (2013). Standing by your organization: The impact of organizational identification and abusive supervision on followers' perceived cohesion and tendency to gossip. Journal of Business Ethics, 118(3), 623-634. https://doi.org/10.1007/s10551-012-1612-z

Dzansi, L. W., Chipunza, C., \& Monnapula-Mapesela, M. (2016). Municipal Employees' Perceptions Of Political Interference In Human Resource Management Practices: Evidence From The Free State Province In South Africa. The International Business \& Economics Research Journal (Online), 15(1), 15. https://doi.org/10.19030/iber.v15i1.9572

Ellwardt, L., Wittek, R., \& Wielers, R. (2012). Talking about the boss: Effects of generalized and interpersonal trust on workplace gossip. Group \& Organization Management, 37(4), 521-549. https://doi.org/10.1177/1059601112450607

Farley, S. D., Timme, D. R., \& Hart, J. W. (2010). On coffee talk and break-room chatter: Perceptions of women who gossip in the workplace. The Journal of Social Psychology, 150(4), 361-368. https://doi.org/10.1080/00224540903365430

Fernandes, S., Kapoor, H., \& Karandikar, S. (2017). Do We Gossip for Moral Reasons? The Intersection of Moral Foundations and Gossip. Basic and Applied Social Psychology, 39(4), 218-230. https://doi.org/10.1080/01973533.2017.1336713

Ferrari, F. (2015). In Praise of Gossip: The Organizational Functions and Practical Applications of Rumours in the Workplace. Journal of Human Resources Management Research, b1-8. https://doi.org/10.5171/2015.854452 
Foster, E. K. (2004). Research on gossip: Taxonomy, methods, and future directions. Review of General Psychology, 8(2), 78. https://doi.org/10.1037/1089-2680.8.2.78

Fox, K. (2001). Evolution, Alienation and Gossip. The role of mobile telecommunications in the 21st century. Social Issues Research Center: Oxford. Retrieved from http://www. sirc. org/publik/gossip.shtml

Gobind, J., \& Ukpere, W. I. (2013). Idle Gossip and Dismissal: A Breeding Ground for Workplace Litigation. Journal of Communication, 4(2), 111-122. https://doi.org/10.1080/0976691X.2013.11884814

Hamman, C., \& Kruger, L.-M. (2017). Gossip girls: The power of girls' gossip in a low-income South African community. Critical Arts, 31(1), 1-17. https://doi.org/10.1080/02560046.2017.1300822

Kurland, N. B., \& Pelled, L. H. (2000). Passing the word: Toward a model of gossip and power in the workplace. Academy of Management Review, 25(2), 428-438. https://doi.org/10.5465/amr.2000.3312928

Pathak, S. (2014). Gossiping in Indian service cluster: A brief empirical study. Res J Commer Behav Sci., 3, 1-9.

Van Vuuren, H. (2014). South Africa: Democracy, corruption and conflict management. Democracy Works.

Wu, L.-Z., Birtch, T. A., Chiang, F. F., \& Zhang, H. (2018). Perceptions of negative workplace gossip: A self-consistency theory framework. Journal of Management, 44(5), 1873-1898. https://doi.org/10.1177/0149206316632057

Yang, C., Minjock, R., Voss, B. E., \& Colarelli, S. M. (2014). Gossip in Organizations: From an Evolutionary Psychological Perspective. Paper presented at the Academy of Management Proceedings. https://doi.org/10.5465/ambpp.2014.69

Yue, A. R. (2013). Talking about gossip at work.

Zhao, H., Peng, Z., \& Sheard, G. (2013). Workplace ostracism and hospitality employees' counterproductive work behaviors: The joint moderating effects of proactive personality and political skill. International Journal of Hospitality Management, 33, 219-227. https://doi.org/10.1016/j.ijhm.2012.08.006 